\begin{abstract}
Purpose: To develop and evaluate a pilot project for succession management among health faculty academics at one Australian University. Aims included enhancing organizational stability and equal opportunity goals; developing personal leadership capacity; promoting staff satisfaction with and motivation for academic leadership; and providing opportunities for mentoring.

Design/methodology: A six month program was developed for middle level academics from each of the nine schools in the faculty with an interest in leadership. The program consisted of formal weekly sessions addressing University and general leadership topics, communication, decision-making, working with change, selfmanagement and career development. Participants were assisted by mentors and sponsors and completed a project for the faculty. The program was evaluated using Kirkpatrick's model to gauge participants' reactions, knowledge, behavior change and plans for the future from a set of questions on knowledge, skills, and motivation for leadership on entry to and completion of the program. Mentors provided feedback on their experience.

Findings: Eight participants ( 4 male, 4 female) completed the program, all rating it highly satisfactory. They identified specific aspects of leadership knowledge, particularly in interpersonal skills and confidence; changes in their perceptions of leadership, and motivation to embrace leadership roles in future. Mentors were invaluable to their development as leaders and reported high satisfaction with the role. Research limitations/implications: Program confined to one faculty and setting but will be extended to a broader study.

Practical implications: Development of a useful model for succession planning. Social implications: Potential for improved Academic leadership.

Originality/Value: An evolving model for succession management.
\end{abstract}

Keywords: Academic leadership, succession planning, academic capacity building, organizational leadership, program evaluation, mentorship

Word count: 4319 


\section{Leadership Succession Management in one University Health Faculty}

\section{Introduction}

Universities have experienced profound changes over the past three decades, with considerable growth in size and complexity, and a public expectation that they will become more entrepreneurial, financially self-sufficient, innovative, and accountable for their performance (de Boer and Goedegebuure, 2009). Among the most significant shifts is a transformation toward a public organization model with accompanying changes in power and authority relations (Santiago et al., 2008). These changes reflect the modern University as a corporate enterprise with management structures designed to respond to multiple demands that transform the institutions into well developed systems (de Boer and Goedegebuure, 2009, Marginson and Considine, 2000). This corporatization of Universities poses a number of challenges for senior executives, including the need to encourage middle level leaders to bridge the divide between academic and managerial cultures efficiently and effectively. Yet many academics, including those in Australian universities, have expressed scepticism about leadership and management, preferring to embrace the more scholarly roles of research and teaching (Bradley et al., 2008).

This paper outlines the approach taken by the health faculty at one Australian University to develop a program of leadership succession management that will help provide a pipeline of middle-level leaders to undertake roles such as Heads of Schools and Directors of Research Centres. The need for succession management was seen by senior executives in the faculty to be both critical and urgent in the context of an aging academic workforce, impending vacancies at the level of middle management, and a lack of best practice models for academic leadership development. The program was based on the premise that investing in succession management could make a significant contribution to academic culture and a University's capacity to retain intellectual and knowledge capital.

\section{The need for succession planning}

Many academic groups, including those in the health professions, are experiencing a shortage of qualified successors (ABS, 1999, Jacobson et al., 2010, Van Amburgh et al., 2010). Yet few studies exist to guide succession planning in the academic arena (Meek, 2007). This is a serious omission from the academic research agenda, particularly in the context of an increasingly managerial ethos within University culture that has effectively 'renormed' the academic profession (Meek, 2007). The focus on managerialism and a proliferation of bureaucratic structures has created unique challenges for University leaders. These include the necessity to identify, retain and nurture high quality staff members who will assume responsibility for significant elements of core University business, which, in turn, means resolving tensions between academic and management roles (Nagy, 2010). A study of 513 middle and top level academic leaders in Australian Universities indicated that there is a need to develop staff leadership capacity in five domains: academic activities, networking, management and administration, planning and policy development, and managing staff (Scott et al., 2008). These activities require strategies for change management, including the need for senior leaders to value the development of managerial skills among middle level staff such as Heads of School or Research Directors. 
In the health professions, clinical and intellectual endeavours that attract collegial respect tend to be valued more highly than leadership (Jacobson et al., 2010). The departmental mission is often framed in terms of the primacy of clinical practice and patient care, focusing on educating the professional workforce and recruiting researchers rather than administrators (Detsky, 2010). However, with an identified need for leadership within and external to the University, some medical faculties have begun to develop joint programs in medicine and management (Ackerly et al., 2011). Others are investing in mentorship programs to cope with both succession planning in the academic environment and the business tasks of healthcare management (Grigsby et al., 2004, Searle et al., 2011).

\section{Changes in the academic workforce}

Significant changes are also occurring in the academic workforce because of generational differences. Contemporary workplaces can have up to four generations among staff, each tending to perceive workplace culture and their personal leadership aspirations in unique ways (Crumpacker and Crumpacker, 2007; Hills, 2008). The combination of staff with differing histories and expectations means that succession planning programs must be developed to accommodate differences (Pleotis Howell et al., 2009). Although there is a dearth of empirical research for multigenerational behavior in the academic workforce, it appears that younger workers are more mobile than previous generations, often placing a higher value on family needs than the mission of their employer (Crumpacker and Crumpacker, 2007; Moye and Swan, 2009, Pleotis Howell et al., 2009). On the other hand, the baby boomer generation has been a typically stable workforce, and some researchers suggest that many will continue to delay retirement in order to remain healthy, socially connected, and able to maintain their standard of living in their later years (Dychtwald and Baxter, 2007). Baby boomers who stay in the workforce represent a major resource in terms of mentoring younger academics, helping to ensure knowledge transfer, retention of institutional memory, and a culture of continuous development (Hart, 2007; Palumbo et al., 2009; The HR Leadership Council, 2007). The challenge for University leaders is to manage succession across the generations; overcoming the hesitancy of younger academics to embrace a leadership role, while retaining leadership capacity in more experienced academics.

A systematic succession planning approach at the institutional and faculty level can help maintain both organizational stability and intellectual capital (Carriere et al., 2009; Collins and Collins, 2007). Deliberate, focused planning can build leadership capacity from within, identifying, developing and deploying a pipeline of quality personnel who can help reduce expenses, learning curve errors, and lengthy adjustment periods (Collins and Collins, 2007; Redman, 2006, Taylor and McGraw, 2004). One objective of succession management is to achieve alignment between skill, aspiration, satisfaction, competence, connection and culture (Hills, 2008). Ensuring suitable people for significant roles, and motivating them to become a learning resource, can also help inspire incumbents to embrace different and higher level roles by sending a message about how they are valued within the organization (Clutterbuck, 2005; Redman, 2006). Studies also show that cultivating diversity in gender, race and cultural competence among academic leaders can have an important impact beyond the University; for example, in delivering effective healthcare, especially when the leaders role model greater understanding of people and their health behaviors (Dannels et al., 2009). 


\section{Succession management programs}

Most succession management programs reported in the literature have been developed for the business community. The programs are based on relatively similar principles: they are long-term, focusing on the needs of the organization as well as future job competencies; they use objective assessments of leadership potential, add value to the organization as well as the individual, and are open and transparent (Overstreet and James, 2005). Carriere et al.'s (2009) integrative review of succession planning programs identified eight strategies for succession planning. These included strategic planning, identifying desired needs and skills, identifying key positions, detecting possible succession candidates, mentoring and coaching, instituting developmental processes, ensuring adequate resources, and evaluation. Programs generally begin by mapping the existing workforce to analyse the demographic distribution and leadership potential (Crumpacker and Crumpacker, 2007; Dutra and Griesedieck, 2010). The next step is identification of the leadership gaps. Ponti (2009) suggests that this can be done as a 'migration risk assessment', where critical success factors can then be prioritized, and top performers can be mentored and coached.

Mentoring and coaching are crucial elements in leadership development and succession planning (Clutterbuck, 2005; Redman, 2006; Sawatzky and Enns, 2009; Shirey, 2008). Mentoring helps people develop a non-vertical career path, sometimes with unconventional moves. It allows a reflective space for conversations that may have been suppressed by the work environment; helping to establish networks and helping people extract more value from their current role (Clutterbuck, 2005). Some programs also use an internship model, where aspiring leaders work alongside a leader-mentor for a defined period of time (Wendler et al., 2009). This type of on-thejob coaching helps the individual create and negotiate with the organization an imaginative and sustainable development role, as well as parallel futures and strategies that can be simultaneously focused and highly flexible (Clutterbuck, 2005). Key elements of mentorship programs include helping potential leaders understand leadership attributes relative to the organization; facilitating their development through new knowledge development and learning activities; exposing them to successful leaders, and transferring technical skills and key organizational knowledge (Safi and Burrell, 2007).

Taylor and McGraw's (2004) study of succession management in Australian-based organizations was aimed at identifying how organizations make succession decisions, what characteristics of succession management impact on organizational effectiveness, and how these programs affect organizational performance. The characteristics of successful succession planning programs identified in their study were high level involvement by senior leaders, line management involvement in identifying candidates, developmental assignments as part of the process, and linking succession management to business strategies (Taylor and McGraw, 2004). The Taylor and McGraw study is unique, as most Australian Universities have yet to develop evidence-based succession management initiatives. Some have information about succession management on their website, but no indication as to whether or not programs are being systematically evaluated. Our program was designed to begin to fill this gap by evaluating one approach to facilitating academic leadership. 


\section{The pilot program for leadership succession}

The aims of the six month pilot program were to:

- maintain continuity in achieving the vision and goals of the health faculty as well as organizational stability,

- provide individual and organizational growth opportunities,

- provide a reflective, creative space for future leaders to develop personal capacity,

- nurture staff satisfaction with academic leadership roles through mentoring,

- enhance the faculty's capabilities for achieving equal opportunity goals.

The program was conceptualized within the theory of transformational leadership. This is based on the idea of the leader as a visionary and dynamic facilitator; one who willingly embraces leadership and works with others to inspire and empower, building capacity by engendering trust and understanding (Burns, 1978). Transformational leaders' reflexive activities lead to self-understanding and consistency between values, beliefs and actions, which reflects emotional competence (Porter-O'Grady and Malloch, 2003). Leadership competence is expected to complement expertise, create flexibility and prepare participants to articulate expectations for the future (Ward, 2002). Within this framework, the eight steps identified by Carriere et al., (2009) were undertaken. The strategic plan was launched by the Dean, Academic, who assembled an advisory group to identify key positions and the needs, skills and positions required. The group then identified a strategy for recruiting succession candidates; identified potential mentors, and made decisions about the program resources, components, mode of delivery, and evaluation approach.

The program components were selected for their focus on self-assessment and selfdevelopment as a transformational leader. These were designed to acknowledge that transformational leadership is a shared, inclusive process and linked to followership (Jackson and Parry, 2008). Such an approach emphasizes mutual development of capacity between the leader and those in the work group or team: the school, department, faculty or research centre/unit. Mentors were an important aspect of the program, as the mentorship relationship was considered fundamental to tailoring personal leadership capacity to individual strengths and needs (Lussier and Achua, 2001; Sawatzky and Enns, 2009). Elements of the program are illustrated in Figure 1.

\section{Participant recruitment and sponsorship}

Initial mapping of demographic data and leadership potential indicated that appointments of several of the Heads of Schools and/or Research Directors were due for replacement within twelve months from the start of the pilot program. The program was announced to all nine schools in the health faculty through a letter from the Dean, requesting an expression of interest (EOI) from the pool of 97 Senior Lecturers and 35 Associate Professors from who may be interested in developing their leadership capacity. The applicants were to be drawn from those who had not previously been a Head of School or Research entity. Candidates were advised that they were required to attend six leadership development sessions, with a commitment to engage with a mentor for a further six months beyond the formal program. They were also required to provide evaluative feedback on the program, and agree to mentor another potential participant at the end of the program as well as participating in a group project at the end of the semester. 
The two most senior leaders in the health faculty, the Pro Vice Chancellor and the Dean, Academic assumed the role of program sponsors. In this context, they identified two projects of significance to their respective portfolios, which were to be undertaken by the program participants over a three month period at the completion of the formal components of the program. The projects were aimed at engaging participants in one of two groups, to undertake an authentic leadership role that would have substantial value to the faculty. The leadership development projects were focused on helping participants develop cognitive and interpersonal skills with the two sponsors enacting a coaching role. All authors participated in the program by presenting one or more of the formal components. Additional presentations were provided by the Pro-Vice Chancellor, the Dean, Academic, and several external experts in particular aspects of the program (the Myers-Briggs Inventory, Work-Life Balance, University Leadership and Mission).

\section{Pilot study evaluation}

The program was evaluated using Kirkpatrick's four levels of evaluation (Kirkpatrick and Kirkpatrick, 2005) to provide empirical data as to the viability of the program for continuation, and its applicability for other faculties and contexts. The Kirkpatrick model is widely used in training and development programs. It consists of the following: Level 1: Reaction - identifying what participants need to find out, evaluating their reactions and written comments, particularly in terms of satisfaction and suggestions for improvement; Level 2 - Learning - examining whether concepts, principles and techniques being taught are understood, developing and/or improving skills and changing attitudes; Level 3 - Behavior - the extent to which workplace behavior changed as a result of the program; and Level 4 - Results - which would be indicated by newly acquired skills, or aspirations for leadership. Ethical approval to evaluate the pilot project was granted by the University Human Ethics Review Committee. All participants were provided with an information letter explaining the evaluation research, and each signed a consent form to participate in the study.

\section{Data collection and analysis}

A semi-structured survey tool was developed to evaluate the program (Figure 2). The evaluation goal was to examine reaction, learning and behavior by identifying their satisfaction with the program, and changes in their self-perceived knowledge, skills, behaviors and motivation for leadership as measured by:

- Participant satisfaction with program components;

- Leadership diagnostics - Myers-Briggs Inventory, Reflected Best Self (http://www.mindtools.com/pages/article/newCDV_61.htm);

- Participant perceptions of the link between program components and their knowledge, skills and aspirations/motivation to undertake a leadership role;

- Self-reported transfer of information from the program into changes in behavior in their current academic role, or personal/social/cultural roles;

- Plans for education, research, or other opportunities;

- Identification of incentives, disincentives, 'critical moments' that facilitated or constrained ongoing capacity development and/or application of knowledge and skills;

- Mentor feedback on their perceptions of leadership capacity for the group. Mentors were asked to rate their satisfaction with the mentor-mentee relationship on a scale of 1-5, and to provide open-ended comment on the experience of being a mentor. 
The analysis included data from eight participants as two withdrew from the program; one because of promotion and the other because of a transfer to another faculty. Demographic data were analysed using descriptive statistics, and responses to the semi-structured interview and open-ended survey questions were categorized through content analysis.

\section{Results}

Eight academics completed the program, four males and four females aged between 37 and 47 years, with a mean age of 42 . Their experience as academics ranged from 4-16 years $(X=8.5)$, and they had been in their current role an average of 5 years.

Reactions: Participants all reported being satisfied with the program, with most of the program components being rated 4-5 out of 5. They reported their reasons for entering the program as personal and professional leadership development. All believed leadership was important to success in their current role and all intended to apply for a further leadership position. All participants reported changes in their motivation for the leadership role.

\section{"My motivation increased by three times". \\ "Having the explanation of emotional and interpersonal skills and relying less on technical skills in leadership is a strength" \\ "Increased understanding of the role has made me more conscious of the need to consider leadership roles and their impact on self/family/ work" \\ "I am thinking more broadly about differences people bring to the table"}

Critical moments were identified as being accepted into the program; being exposed to the MBI for the first time and using this as a tool to understand personal strengths and weaknesses. One person found that meeting the mentor for the first time was significant, and another identified the accounts of leaders' personal journeys as critical moments. Yet another believed that learning to think beyond 'tribal goals' to interpersonal and emotional skills was a critical moment.

Incentives were listed as gaining recognition, satisfaction, and career progression; feeling comfortable with "big picture skills and competencies"; being more effective; and hearing examples of success. Only a few disincentives were identified, which included having inadequate time for reflection;

Reactions from the five senior leaders who had entered into a mentoring role indicated that all had enjoyed the process. All were in senior positions in the faculty. Mentors described their interactions as being responsive to the mentee's needs. The relationship was one of trust; explained by one mentor as helping the mentee 'put it out there'. All mentors found the relationship gradually more informal with each encounter. The themes emerging from their interactions included helping with the mentee's potential; validating their ideas; discussing how to position themselves for achieving medium and long-term goals and strategies; working through how to manage 'upwards'; that is, with people at higher academic status; and helping the mentee see the 'big picture'. At the group or faculty level, discussion took place around the group vision, explaining personal management styles and decisionmaking. Another group-level leader addressed strategies for achieving work-life 
balance. A research mentor explained that he had enjoyed sharing and discussing the mentor's expertise as well as his own. The most senior member of the faculty had also acted as a mentor, allowing the mentee to shadow him as Pro Vice Chancellor (PVC) for a day. His reaction to the day's queries and comments were to question "who is the mentor here?", an indication that being asked to explain his actions may have had a positive self-reflexive effect.

Learning: Comments included the desire to learn about strategic directions and leadership structures, to connect and communicate with leaders, achieve a level of self-understanding, and having access to a mentor. They identified changes in knowledge as knowing how to be a more effective leader, having a wider perspective on University complexity and leadership challenges, having deeper insights and personal strengths, and understanding strengths and anchors.

"I have knowledge of my strengths as others see them and I'm applying these to my current situation".

"I am reading outside the program about leadership"

"My knowledge has improved substantially especially from the presentation on

" "Working with others, working with change"”

"realizing that what academics want is different to organizational needs"

"recognizing poor leadership in my manager"

"there is so much responsibility and so little reward in leadership".

\section{Behavior:}

Changes in skill focused on communication, reflective management, confidence, and self-awareness. All believed their leadership skills had increased from the program.

"I have [sic] greater consultation, give clear directions with those I am leading".

"I have the skills to identify others' preferences and engage with difference";

"My leadership skills are more reflective".

Results:

Most intended to pursue leadership roles, some of which were University based, while in two cases, individuals had decided to seek senior leadership opportunities with their respective professional bodies.

\footnotetext{
"better prepared to take on leadership"

"inspired to listen"

"will take opportunities for committees"

"I would like a leadership role but I'll consolidate my research first"

"I am more focused now in research"

"I need to learn about budgets"

"I am building broader relations"

"more reflective and understanding of personalities"

"better prepared to differentiate my role from that of my staff"

"The program reinforced the importance of multicultural courses, but I think cultural differences are not as important as treating people fairly and with respect".
} 
All found the mentoring experience helpful.

"My mentor is excellent, influential, validates my role". General comments were favourable "great initiative", "important", "enjoyable"," worthwhile”, "enjoyed others", "new perspectives", "given me greater appreciation and motivation for leadership". They also enjoyed the Reflected Best Self exercise, as indicated in comments such as:

"I'm more circumspect in making decisions",

"confident", "reminds me not to take my strengths for granted"

"I'm better at gathering information, seeing me as others see me".

Suggestions for program improvements included having the opportunity to shadow a leader early in the program, to engage with mentors sooner, to have more case examples, additional focus on practical aspects of leadership, and to have more discussion time with one another. Of the two group projects, one has been delayed, but the project on internationalization has been successfully completed. The group conducted a mapping exercise of international activities in the faculty, evaluated the relevant strategic and financial plans, conducted a SWOT analysis and assessed the congruence between University and faculty goals and their implementation within the nine schools of the faculty. The group produced a background paper recommending a new set of internationalisation strategies linked to research, learning, teaching and developing global citizenship, which was subsequently presented to the health faculty executive.

\section{Discussion}

The immediate value of this small pilot program lies in providing a baseline of evaluative data that can be refined and used for succession planning models in the University and perhaps beyond. The program was perceived as invaluable to those who participated in developing their leadership skills, as well as those who planned the program around the succession planning needs of the faculty and the University. The major advantages for participants were gaining a deeper understanding of University culture; recognising that there are rewards and incentives in academic leadership; becoming aware of the need for forward planning and career positioning, and feeling confident in decision-making, largely due to the mentors and several of the learning exercises. Mentors and sponsors also gained from the program, through their close interaction with participants and, with the internationalization project, by receiving a set of recommendations from the fresh perspective of new leaders. Based on the evaluation data, the program is being refined with some rearrangement of content and sequencing, and repeated with a larger group of health academics. For example, sessions outlining 'How the University Works' and 'Working with People, Working with Change' will be provided earlier in the program as a foundation for other components. The program will also be adapted for other faculties in the University who wish to undertake this approach to developing academic leaders.

Higher education institutions are often in a difficult position to recruit strong leaders. Adequate renewal of academic professionals cannot be expected from the traditional 'replacement' approach of the past, which is reactive rather than proactive (Meek, 2007). Instead senior leaders must begin to adopt strategies from the business community in order to operate within a corporate ethos while retaining their 
ideological commitment to collegiality, collaboration and participative decisionmaking (Bolden et al., 2009). This is a tall request from institutions that must deliver on competing priorities, which include mass education, producing cutting-edge research, and maintaining close engagement with employers and the international community (Bolden et al., 2009). Although the study was limited to one setting and a small number of participants, we believe that it provides a nascent model for future planning, particularly within the context of transformational leadership.

A feature of transformational leadership is the focus on conveying the organizational vision in a way that resonates with the values and aspirations of staff members.

Members of the University who delivered components of the program achieved their goal of inspiring and empowering participants, building capacity by engendering trust and understanding of the realities of academic life. This was evident in the favourable reactions of participants and their aspirations and plans. We conclude that a model that builds from within the academic environment may be more helpful for succession planning than engaging external consultants who may not have the in-depth knowledge of how Universities work. There is also a need to nurture a culture of mentorship among senior University leaders. We are currently launching our second succession management program, in which all eight participants from the pilot study will act as mentors either for members of the next future leaders group or for others in their respective schools. This is seen as a strength of the program in ensuring its sustainability.

In the past, academic mentorship was ad hoc, depending on the graciousness of Professors and senior leaders and their particular commitment to the next generation of potential successors. In today's University environment mentorship must be seen as integral to the role of all academics, particularly in the face of impending faculty shortages. The resistance to change that is evident in many academic institutions may be better overcome when senior leaders role model leadership as an integral part of scholarship (Harris et al., 2003). This is particularly true of health faculties, where current students will be challenged to adapt to rapidly changing societal changes and the tripartite missions of patient care, research and education, all of which require leadership skills (Grigsby et al., 2004). As university leaders are aware, academic middle managers must be more strategic than their predecessors, particularly in sustaining the performance of the school, department or work group (De Boer and Goedegebuure, 2009). Evidence from the literature as well as our pilot study indicates that succession planning will be pivotal to their success. The model presented in this paper offers a starting point for meeting this important need for the contemporary Academic workforce. 


\section{References}

Ackerly, D., Sangvai, D., Udayakumar, K., Shah, B., Kalman, N., Cho, A., Schulman, K., Fulkerson, W. \& Dzau, V. (2011), "Training the next generation of physician executives: An innovative residency pathway in management and leadership", Academic Medicine, Vol 86 No. 5, pp. 575-579.

Australian Bureau of Statistics (1999), Labour force projections, Australia, 19992016, AGPS, Canberra.

Bolden, R., Petrov, G., Gosling, J. \& Bryman, A. (2009), "Leadership in higher education: Facts, fictions and futures", Leadership, Vol. 5 No. 3, pp. 291-298.

Bradley, D., Noonan, P., Nugent, H. \& Scales, B. (2008), Review of Australian Higher Education: Final Report, AGPS, Canberra.

Burns, J. (1978), Leadership, Harper \& Row, New York.

Carriere, B., Cummings, G., Muise, M. \& Newburn-Cook, C. (2009), "Healthcare succession planning: An integrative review". Journal of Nursing Administration Vol. 39 No. 12, pp. 548-555.

Collins, S. \& Collins, K. (2007), "Changing workforce demographics necessitates succession planning in health care", The Health Care Manager, Vol. 26 No. 4, pp. 318-325.

Clutterbuck, D. (2005), "Succession planning: a developmental approach", Development and Learning in Organizations, Vol 19 No. 5, pp. 11-13.

Crumpacker, M. \& Crumpacker, J. (2007), "Succession planning and generational stereotypes: Should HR consider age-based values and attitudes a relevant factor or a passing fad?" Public Personnel Management, Vol. 36 No.4, pp. 349-369.

Dannels,, S., McLaughlin, J., Gleason, K., McDade, S., Richman, R. \& Morahan, P. (2009), 'Medical school deans' perceptions of organizational climate: Useful indicators for advancement of women faculty and evaluation of a leadership program's impact", Academic Medicine, Vol. 84, No. 1, pp. 67-79.

De Boer, H. \& Goedegebuure, L. (2009), "The changing nature of the academic deanship", Leadership, Vol. 5 No. 3, pp. 347-364.

Detsky, A. (2011), "How to be a good Academic leader", Journal of General Internal Medicine, Vol. 26 No. 1, pp. 88-89.

Dutra, A. \& Griesedieck, J. (2010), "Succession success", Leadership Excellence 14 May, pp. 14-15.

Dychtwald, K. \& Baxter, D. (2007), "Capitalizing on the new mature workforce". Public Personnel Management, Vol. 36 No. 4, pp. 325-334. 
Grigsby, R., Hefner, D., Souba, W. \& Kirch, D. (2004). "The future oriented department chair”, Academic Medicine, Vol. 79 No. 6, pp. 571-577.

Grigsby, R., Aber, R. \& Quillen, D. (2009), "Interim leadership of academic departments at US medical schools", Academic Medicine, Vol. 84 No. 10, pp.13281329.

Harris, D., DaRosa, D., Liu, P. \& Hash, R. (2003). "Facilitating academic institutional change: Redefining scholarship", Family Medicine, Vol. 35 No. 3, pp. 187-194.

Hart, K. (2007), "The aging workforce: implications for health care organizations", Nursing Economics, Vol. 25, No. 2, pp. 101-102.

Hills, A. (2009), "Succession planning - or smart talent management?", Industrial and Commercial Training, Vol, 41 No. 1, pp. 3-8.

Jackson, B. \& Parry, K. (2008), A very short, fairly interesting and reasonably cheap book about studying leadership. Sage, Los Angeles.

Jacobson, S., Travis, M., LalithKumar, S., MacPhee, E., Reynolds, C., Ryan, N., Roth, L. and Kupfer, D. (2010), "Preparing the next generation of leaders in clinicianeducation and academic administration", Academic Psychiatry, Vol. 34 No. 3, pp. 224-228.

Kirkpatrick, D. \& Kirkpatric, J. (2005), Transferring learning to behavior: Using the four levels to improve performance, Berrett-Koehler Publishers, San Francisco.

Lussier, R. \& Achua, C. (2001), Leadership: theory, application, skill development, South Western College Publishing, Cincinnati.

Marginson, S. \& Considine, M. (2000), The Enterprise University, Cambridge University Press, Melbourne.

Meek, V. L. (2007), "Succession planning and Australian higher education", in Dempster, N. (Ed), The treasure within leadership and succession planning, Australian College of Educators, Deakin West, pp 111-125.

Moye J., Swan, B. (2009), "Growing ambulatory care nurse leaders in a multigenerational workforce”, Nursing Economics, Vol. 27 No. 6, pp. 408-415.

Nagy, J. (2010), "Leadership and management in the academy", Newsletter of the Business/Higher Education Round Table Vol 28, pp. 7-8.

Overstreet, J. \& Jones, J. (2005), "Developing leadership one step at a time: The Oklahoma experience", Topics in Community Corrections pp. 24-31.

Palumbo, M., McIntosh, B., Rambur, B. \& Naud, S. (2009), "Retaining an aging nurse workforce: Perceptions of human resource practices", Nursing Economic, Vol. 27 No. 4, pp. 221-232. 
Pleotis Howell, L., Joad, J., Callahan, E., Servis, G. \& Bonham, A. (2009), "Generational forecasting in academic medicine: A unique method of planning for success in the next two decades", Academic Medicine, Vol. 84 No. 8, pp. 985-993.

Ponti, M. (2009), "Transition from leadership development to succession management", Nursing Administration Quarterly, Vol. 33 No. 2, pp. 125-141.

Porter-O'Grady, T \& Malloch, K. (2003), Quantum leadership: a textbook of new leadership, Jones and Bartlett, Mississauga.

Redman, R. (2006), "Leadership succession planning. An evidence-based approach for managing the future", Journal of Nursing Administration, Vol. 36 No. 6, pp. 292297.

Safi, A. \& Burrell, D. (2007), "The role of mentoring in succession planning and talent in non-profit and governmental organizations", International Journal of Business and Management, Vol. 2 No. 5, pp.167-174.

Santiago, P., Tremblay, K., Basri, E. \& Arnal, E. (2008), Tertiary Education for the Knowledge Society, OECD, Paris.

Sawatzky, J. \& Enns, C. (2009), "A mentoring needs assessment: Validating mentorship in nursing education”, Journal of Professional Nursing, Vol. 25 No. 3, pp. 145-150.

Scott, G., Coates, H. \& Anderson, M. (2008), Learning Leaders in time of change: Academic leadership capabilities for Australian higher education, University of Western Sydney, Australian Council for Educational Research, Sydney.

Searle, N., Thibault, G. \& Greenberg, S. (2011), "Faculty development for medical educators: Current barriers and future directions", Academic Medicine, Vol. 86 No. 4, pp. 405-406.

Shirey, M. (2008), "Building the leadership development pipeline. A 5 step succession planning model”, Clinical Nurse Specialist, vol. 22 No. 5, pp. 214-217.

Taylor, T. \& McGraw, P. (2004), "Succession management practices in Australian organizations", International Journal of Manpower, Vol. 25 No. 8, pp.741-758.

The HR Leadership Council (2007). The business case for succession management, Corporate Executive Board, London.

Van Amburgh, J., Surratt, C., Green, J., Gallucci, R., Colbert, J., Zatopek, S. and Blouin, R. (2010), "Succession planning in US Pharmacy Schools", American Journal of Pharmaceutical Education, Vol 74 No. 5, pp. 1-7.

Ward, K. (2002), “A vision for tomorrow: Transformational nursing leaders”, Nursing Outlook, Vol. 50, pp. 121-6. 
Wendler, M., Olson-Sitki, K., Prater, M. (2009), "Succession planning for RNs", Journal of Nursing Administration, Vol. 39 No. 7/8, pp. 326-333. 
1. Introduction - What is a leader in the University sector? The

Faculty Vision

2. Leadership, Communication and Ethical Decision-Making

3. Reflected Best Self Exercise (www.mindtools.com)

4. The Mentor-Mentee Relationship

5. Working with Others, Working with Change

6. Managing the Self: The Myers Briggs Inventory \& Exercises

7. Pathways to Leadership: Influential Leaders' Journeys

8. Developing Your Career, Achieving Work-Life Balance

9. How the University Works

10. Group projects:

1: Induction/orientation of new academics;

2. Faculty Internationalisation

Fig. 1. Pilot program components 
1. Briefly explain your reason(s) for undertaking the program

2. Prior to hearing about the program, had you intended to apply for a leadership position?

3. How important is leadership to your current role?

4. Please rate your satisfaction with each aspect of the program on a scale of 1-5 where 5 is very satisfied

5. Please comment on how your knowledge, skills motivation for leadership have changed

6. Describe any critical moments, incentives, disincentives that were important to your leadership development

7. Describe any new plans/intentions for education, research, leadership

8. Are there any aspects of program that have changed (enhanced or constrained) your role in the workplace, or personal roles?

9. Any changes in perceptions of cultural issues: workplace/personal?

10. Can you comment on the role of your mentor in leadership development

11. How important do you think leadership is to success in your current role?

12. General comments, any major changes from Reflected Best Self exercise? Group project?

13. Do you have any suggestions for future programs?

Figure 2: Pilot project evaluation questions 